\title{
Plasma oestrogen fractions in postmenopausal women receiving hormone replacement therapy: influence of route of administration and cigarette smoking
}

\author{
J Geisler, I H Omsjø ${ }^{1}$, S I Helle, D Ekse, T Silsand ${ }^{2}$ and \\ P E Lønning
}

Department of Therapeutic Oncology and Radiophysics, Haukeland University Hospital, N-5021 Bergen, Norway

${ }^{1}$ Laboratory for Osteoporosis, 0518 Oslo, Norway

${ }^{2}$ Central Laboratory of the Telemark Central Hospital, 3900 Porsgrunn, Norway

(Requests for offprints should be addressed to P E Lønning

\begin{abstract}
The aim of this study was to determine the impact of the administration route and cigarette smoking on plasma oestrogen levels during oral and parenteral oestrogen replacement therapy (ERT). Fourteen healthy postmenopausal women (six smokers and eight non-smokers) were recruited for a prospective, randomised, crossover study at a private outpatient medical centre in Oslo, Norway. All patients were randomised to receive cyclic therapy with oestradiol and norethisterone orally or by the transdermal route each for a 6 -month period. Plasma levels of oestrone $\left(\mathrm{Oe}_{1}\right)$, oestradiol $\left(\mathrm{Oe}_{2}\right)$ and oestrone sulphate $\left(\mathrm{Oe}_{1} \mathrm{~S}\right)$ were determined using highly sensitive RIA methods before and during hormone replacement therapy given by the oral and transdermal route. Comparing smokers and nonsmokers, plasma levels of $\mathrm{Oe}_{1}, \mathrm{Oe}_{2}$ and $\mathrm{Oe}_{1} \mathrm{~S}$ were all
\end{abstract}

found to be $40-70 \%$ lower in smokers compared with non-smokers when ERT was given orally $\left(\mathrm{Oe}_{1} \mathrm{~S}, P<0 \cdot 05\right.$; $\mathrm{Oe}_{1}$ and $\mathrm{Oe}_{2}, P<0 \cdot 01$ for both). $\mathrm{Oe}_{2}$ given orally caused a higher $\mathrm{Oe}_{1} \mathrm{~S} / \mathrm{Oe}_{2}$ ratio but also a higher $\mathrm{Oe}_{1} / \mathrm{Oe}_{2}$ ratio compared with parenteral therapy in smokers $(40 \cdot 2$ versus $7 \cdot 0, P<0 \cdot 01$; and $3 \cdot 2$ versus $0 \cdot 8, P<0 \cdot 05$ respectively). No significant differences in these parameters in the different test-situations were seen in non-smokers. Except for a lower level of $\mathrm{Oe}_{1} \mathrm{~S}$ in smokers (non-significant), no difference in plasma oestrogen levels between smokers and non-smokers was observed during parenteral therapy. In conclusion, cigarette smoking has been shown to have major impact on plasma oestrogen levels during oral but not during parenteral $\mathrm{Oe}_{2}$ replacement.

Journal of Endocrinology (1999) 162, 265-270

\section{Introduction}

Oestrogen replacement therapy (ERT) is known to improve quality of life and to prevent severe diseases such as osteoporosis (Kiel et al. 1987) and cardiovascular morbidity (Nabulsi et al. 1993) in postmenopausal women. Traditionally administered orally, oestrogens may now be given by the transdermal route.

Due to substantial first pass metabolism (Longcope et al. 1985), oral oestrogens have to be administered in high doses to achieve acceptable plasma levels. Thus, oral ERT is known to influence hepatic synthesis and secretion of several endogenous compounds (Geola et al. 1980). While some of these effects, like increasing levels of high-density lipoproteins, might be beneficial (Lobo 1991), changes in plasma levels of clotting factors probably explain an increased risk of intravascular clotting during ERT (Meade 1982). Therefore, much effort has been made to develop alternative routes of oestrogen administration that bypass the liver such as vaginal and transdermal delivery systems (Laufer et al. 1983, Mandel et al. 1983).

While several studies have compared plasma levels of oestradiol $\left(\mathrm{Oe}_{2}\right)$ and oestrone $\left(\mathrm{Oe}_{1}\right)$ in patients treated with parenteral or oral oestrogens (Chetkowski et al. 1986, Lignieres et al. 1986), little is known about plasma levels of oestrone sulphate $\left(\mathrm{Oe}_{1} \mathrm{~S}\right)$ in patients receiving ERT. Oe $\mathrm{O}_{1} \mathrm{~S}$ is the main circulating oestrogen in postmenopausal women, and recent evidence has focused on plasma $\mathrm{Oe}_{1} \mathrm{~S}$ as an important source to tissue oestrogens in postmenopausal women (Santner et al. 1984). Circulating $\mathrm{Oe}_{1} \mathrm{~S}$ is synthesised from plasma $\mathrm{Oe}_{1}$ and $\mathrm{Oe}_{2}$, and between 50 and $90 \%$ of both oestrogens is converted into $\mathrm{Oe}_{1} \mathrm{~S}$ (Ruder et al. 1972, Lønning et al. 1987, 1989). Liver tissue contains high concentrations of sulphotransferase (Ruder et al. 1972), necessary to synthesise $\mathrm{Oe}_{1} \mathrm{~S}$, and only about $10-20 \%$ of $\mathrm{Oe}_{2}$ administered orally reaches the systemic circulation unmetabolised (Longcope et al. 1985). 
Cigarette smoking is suggested to have anti-oestrogenic effects in women. The mechanisms for these observations are poorly understood, as no study has revealed any significant difference in plasma levels of $\mathrm{Oe}_{1}$ or $\mathrm{Oe}_{2}$ between smoking and non-smoking women. Smoking is known to enhance certain P450 dependent mixed function oxygenases (Conney 1967), some of which also metabolise oestrogens (Bolt 1979). However, plasma Oe and $\mathrm{Oe}_{2}$ are known to have high clearance rates approximating hepatic plasma flow (Longcope \& Williams 1974); therefore, enhancement of enzymes engaged in liver metabolism of plasma oestrogens is expected to have little influence on $\mathrm{Oe}_{1}$ and $\mathrm{Oe}_{2}$ clearance rates in postmenopausal women (Wilkinson \& Shand 1975, Lønning \& Kvinnsland 1988) and to have only minor influence on endogenous $\mathrm{Oe}_{1}$ and $\mathrm{Oe}_{2}$ plasma levels and oestrogen levels following parenteral administration.

Based on the considerations above, this study was designed to test three hypotheses. Our first hypothesis was that $\mathrm{Oe}_{2}$ administered orally, due to excessive first pass metabolism, may produce higher plasma $\mathrm{Oe}_{1} \mathrm{~S}$ levels compared with $\mathrm{Oe}_{2}$ given parenterally. Secondly, we postulated smoking to lower plasma oestrogen levels following oral administration of $\mathrm{Oe}_{2}$. Thirdly, because $\mathrm{Oe}_{1} \mathrm{~S}$, contrary to $\mathrm{Oe}_{1}$ and $\mathrm{Oe}_{2}$, is a so-called 'low extracted compound' with a plasma clearance rate much lower than hepatic plasma flow (about 3-6 1/h) (Longcope 1972), enzyme induction (smoking) may be expected to lower plasma levels of $\mathrm{Oe}_{1} \mathrm{~S}$ also in postmenopausal women receiving parenteral or no ERT.

\section{Materials and Methods}

\section{Human subjects}

Seventeen postmenopausal women who were to receive ERT due to clinical symptoms of oestrogen deprivation were enrolled. Fourteen patients completed both treatment periods and were included for analysis. Median age, weight, height and body mass index were 49.5 years (range 43.0-63.0), $68 \mathrm{~kg}$ (range 44-85), $1.67 \mathrm{~m}$ (range $1 \cdot 56-1 \cdot 78$ ) and $24 \cdot 0 \mathrm{~kg} / \mathrm{m}^{2}$ (range $17 \cdot 6-30 \cdot 1$ ) respectively.

All patients had gonadotrophin levels in the postmenopausal range with absence of menstrual bleeding for 4 to 240 months. Cervical cytology showed regular cells in all patients prior to ERT. None of the patients suffered from diabetes mellitus, liver or renal diseases. One non-smoker received treatment with ergotamine-tartrate for migraine, while all remaining patients received the study drug only. Any other hormone therapy was terminated at least 6 weeks before inclusion in the study.

Six patients smoked 10-20 cigarettes daily; the other patients were non-smokers. None of the patients had a record of alcohol abuse. All patients gave their written informed consent, and the study was approved by the regional ethical committee.

\section{Study procedures}

Patients were randomised to receive cyclical therapy with $\mathrm{Oe}_{2}$ and norethisterone orally (Trisekvens Novo, Novartis, Basle, Switzerland: $17-\beta-\mathrm{Oe}_{2} 2 \mathrm{mg}$ days $1-22$ and $1 \mathrm{mg}$ days 23-28, norethisterone $1 \mathrm{mg}$ days 13-22) or by the transdermal route (Estracomb, Copenhagen, Denmark $\mathrm{Oe}_{2} 50 \mu \mathrm{g} / 24 \mathrm{~h}$ days $1-28$, norethisterone $250 \mu \mathrm{g} / 24 \mathrm{~h}$ days 15-28). The progesterone treatments during oral and parenteral therapy were considered to be equal. Each patient was treated with the assigned treatment for 6 months where after they were switched to the other regimen without any wash-out period. Total time of the investigation period was 12 months. Blood samples were obtained before treatment and after 3, 6, 9 and 12 months on treatment. According to protocol, samples were to be drawn during the second week of the first half of the cycle when patients were treated with $\mathrm{Oe}_{2}$ only in both regimens. All blood samples were obtained in heparinised vials between 0800 and $1000 \mathrm{~h}$ after an overnight fast. While on oral treatment, all patients took their last medication before $2000 \mathrm{~h}$ in the evening to ensure a free interval of at least $12 \mathrm{~h}$ prior to blood sampling on the following day. Plasma was separated by centrifugation and stored at $-20{ }^{\circ} \mathrm{C}$ until time of analysis.

\section{Assays}

Plasma levels of $\mathrm{Oe}_{1}, \mathrm{Oe}_{2}$ and $\mathrm{Oe}_{1} \mathrm{~S}$ were measured as described elsewhere (Lønning et al. 1995) while plasma levels of sex hormone binding globulin (SHBG) were measured using a commercial RIA kit provided by Orion Diagnostica, Espoo, Finland. The biochemical evaluation of the smoking status was done by cotinine measurements in plasma samples (Muranaka et al. 1988) using a modified RIA as published previously (Waage et al. 1992).

\section{Data analysis}

Previous work in our laboratory revealed plasma oestrogen levels in postmenopausal women to be well fitted to a log normal distribution (Lønning et al. 1995). Thus, plasma hormone levels and the ratios between the different oestrogens obtained before and during ERT are given as their geometric mean values with $95 \%$ confidence intervals of the means. The mean value of the two blood samples drawn on each treatment (after 3 and 6 or 9 and 12 months respectively) was used for data analysis. The Mann-Whitney test was used to investigate any difference between smokers and non-smokers in the different test-situations and to compare plasma oestrogen levels during oral and parenteral ERT. Considering the ratios between the different plasma oestrogens before and during 
treatment with the two regimens, these were compared in the three test situations within each patient group using the Friedman test.

\section{Results}

Plasma oestrogen levels obtained before and during oral and parenteral ERT are illustrated in Fig. 1 and given in detail in Table 1, while changes in plasma oestrogen ratios are summarised in Table 2. Concerning pretreatment oestrogen levels, no significant difference comparing smokers and non-smokers could be established, although the mean plasma levels of all oestrogens measured were somewhat lower in smokers.

We found treatment with $\mathrm{Oe}_{2}$ given orally ( $2 \mathrm{mg}$ daily) to cause significant higher plasma levels of all oestrogens compared with $50 \mu \mathrm{g}$ daily given by the parenteral route (Table 1 and Fig. 1). The ratio of $\mathrm{Oe}_{1} \mathrm{~S}$ to $\mathrm{Oe}_{2}$ increased during treatment with oral $\mathrm{Oe}_{2}$, while it decreased during parenteral ERT compared with the pretreatment ratio (this change, however, was significant in smokers only, $P<0 \cdot 01)$. The ratio of $\mathrm{Oe}_{1} \mathrm{~S}$ to $\mathrm{Oe}_{1}$ increased to the same extent during both oral and parenteral ERT in the total patient group; however, the ratio differed significantly between smokers and non-smokers in both treatment situations, with a higher ratio in smokers during oral therapy but a higher ratio in non-smokers during parenteral therapy $(P<0 \cdot 05$ comparing the three test-situations among smokers as well as non-smokers; Table 2).

While no significant difference in plasma levels of $\mathrm{Oe}_{1}$, $\mathrm{Oe}_{2}$ and $\mathrm{Oe}_{1} \mathrm{~S}$ could be established between smokers and non-smokers before initiation of ERT, cigarette smoking caused major changes in plasma hormone levels during oral ERT. In smokers, the mean plasma levels of $\mathrm{Oe}_{1}, \mathrm{Oe}_{2}$ and $\mathrm{Oe}_{1} \mathrm{~S}$ reached $37 \%(P<0 \cdot 01), 27 \%(P<0 \cdot 01)$ and $57 \%$ $(P<0.05)$ of the mean plasma levels found in non-smoking women during oral ERT respectively. In addition, the ratio of $\mathrm{Oe}_{1} \mathrm{~S}$ to $\mathrm{Oe}_{1}$ and $\mathrm{Oe}_{1} \mathrm{~S}$ to $\mathrm{Oe}_{2}$ was higher in smokers compared with non-smokers (Table 2; $P<0 \cdot 05$ and $P<0.01$ respectively comparing smokers to nonsmokers), suggesting a more substantial effect of smoking on plasma $\mathrm{Oe}_{1}$ and $\mathrm{Oe}_{2}$ compared with $\mathrm{Oe}_{1} \mathrm{~S}$ during oral ERT.

No difference in plasma levels of $\mathrm{Oe}_{1}$ and $\mathrm{Oe}_{2}$ between smokers and non-smokers was seen during parenteral treatment. However, we found a non-significant lowering of plasma $\mathrm{Oe}_{1} \mathrm{~S}$ levels in smokers (1034 pM) compared with non-smokers $(1744 \mathrm{pM} ; P=0 \cdot 16)$.

Oral $\mathrm{Oe}_{2}$ increased plasma SHBG values in both smokers and non-smokers (Table 3). The plasma SHBG level increased from pretreatment levels of $64.4 \mathrm{nmol} / 1$ $(95 \%$ c.i. $41 \cdot 4-100 \cdot 2)$ in smokers and $41.6 \mathrm{nmol} / 1$ $(95 \%$ c.i. $29 \cdot 2-59 \cdot 3)$ in non-smokers $(64 \cdot 9 \%$ of the value obtained for smokers, $95 \%$ c.i. $39 \cdot 3-106 \cdot 2 \%)$ to
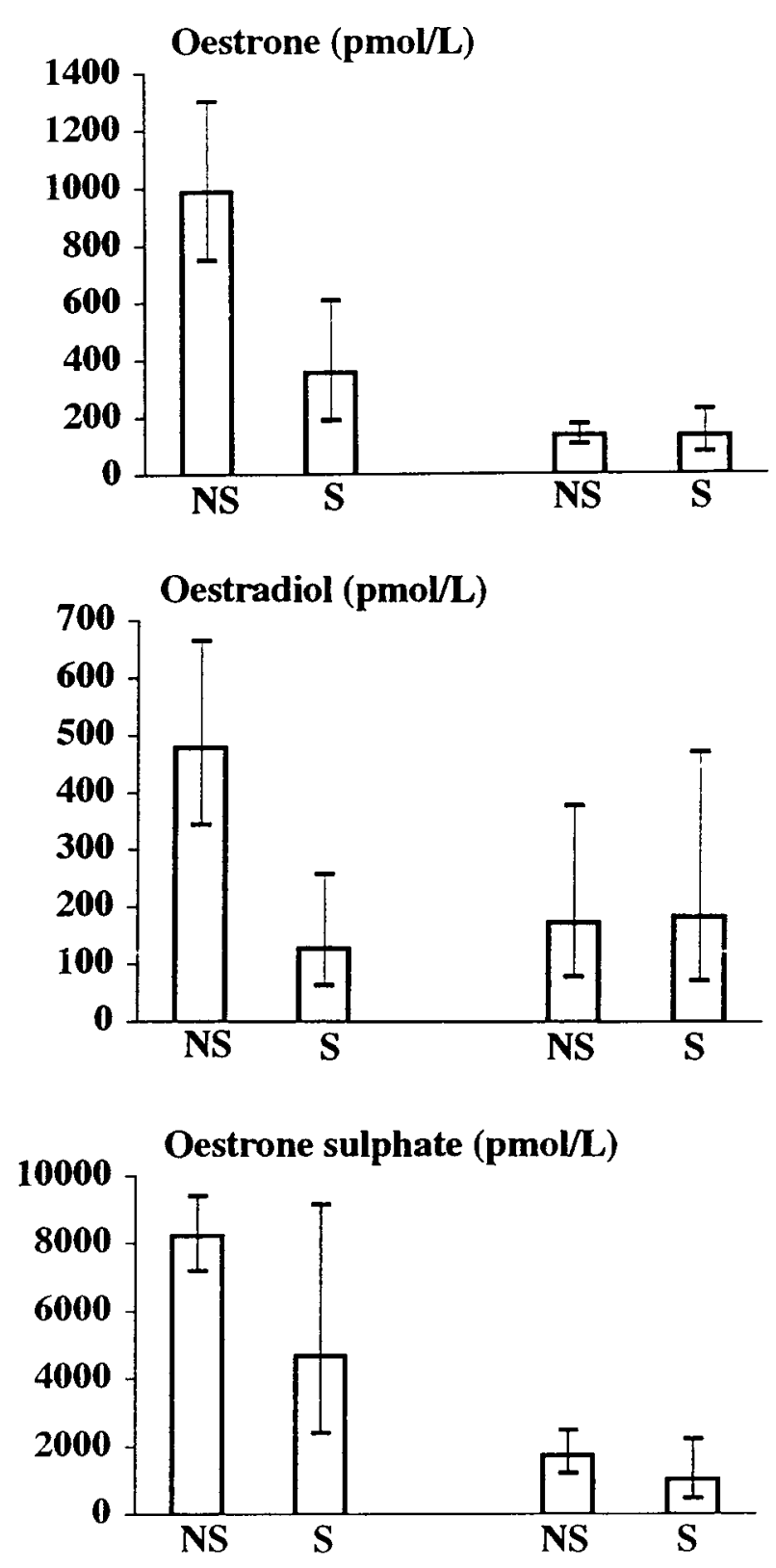

Oral ERT

Parenteral ERT

Figure 1 Plasma levels of oestrone $\left(\mathrm{Oe}_{1}\right)$, oestradiol $\left(\mathrm{Oe}_{2}\right)$ and oestrone sulphate $\left(\mathrm{Oe}_{1} \mathrm{~S}\right)$ during treatment with oral and parenteral ERT in the subgroups of smokers (S) and non-smokers (NS). All oestrogen values are expressed as geometric means with $95 \%$ confidence intervals of the mean.

$88 \cdot 7 \mathrm{nmol} / 1$ (95\% c.i. $63 \cdot 4-124 \cdot 1)$ and $88 \cdot 0 \mathrm{nmol} / 1$ (95\% c.i. 58.7-132.0) during oral treatment respectively (nonsmokers $P<0 \cdot 05$; smokers n.s.). No change in plasma SHBG was observed during parenteral ERT. 
Table 1 Plasma levels of oestrone, oestradiol and oestrone sulphate obtained before and during ERT by the oral or parenteral route (geometrical mean values with $95 \%$ confidence limits of the mean)

\begin{tabular}{|c|c|c|c|c|c|c|c|}
\hline \multirow{2}{*}{\multicolumn{2}{|c|}{ Oestrogen levels ( $\mathrm{pmol} / \mathrm{l})$}} & \multicolumn{2}{|c|}{ Before therapy } & \multicolumn{2}{|c|}{ During oral ERT } & \multicolumn{2}{|c|}{ During parenteral ERT } \\
\hline & & & & & & & \\
\hline $\mathrm{Oe}_{1}$ & smokers ${ }^{\mathrm{c}}$ & 68 & $(38-123)$ & $356^{\mathrm{b}}$ & $(190-608)$ & 133 & $(78-225)$ \\
\hline $\mathrm{Oe}_{1}$ & non-smokers ${ }^{\mathrm{d}}$ & 73 & $(42-127)$ & $987^{b}$ & $(750-1301)$ & 135 & $(104-175)$ \\
\hline $\mathrm{Oe}_{2}$ & smokers & 23 & $(7-76)$ & $128 \cdot 5^{b}$ & $(64-258)$ & $184 \cdot 6$ & $(72-473)$ \\
\hline $\mathrm{Oe}_{2}$ & non-smokers ${ }^{\mathrm{C}}$ & 46 & $(14-144)$ & $479 \cdot 1^{b}$ & (345-665) & $173 \cdot 5$ & (79-379) \\
\hline $\mathrm{Oe}_{1} \mathrm{~S}$ & smokers $^{\mathrm{c}}$ & 417 & $(225-771)$ & $4684^{\mathrm{a}}$ & $(2401-9145)$ & 1034 & $(478-2237)$ \\
\hline $\mathrm{Oe}_{1} \mathrm{~S}$ & non-smokers ${ }^{\mathrm{d}}$ & 549 & $(225-1342)$ & $8226^{a}$ & $(7194-9405)$ & 1744 & $(1221-2487)$ \\
\hline
\end{tabular}

$\mathrm{Oe}_{1}$, oestrone; $\mathrm{Oe}_{2}$, oestradiol; $\mathrm{Oe}_{1} \mathrm{~S}$, oestrone sulphate; significant difference between smokers and non-smokers (Mann-Whitney), a $P<0 \cdot 05$, b $P<0 \cdot 01$; significantly difference in plasma oestrogen levels comparing oral and parenteral ERT (Mann-Whitney), ${ }^{\mathrm{c}} P<0 \cdot 05,{ }^{\mathrm{d}} P<0 \cdot 001$.

Table 2 Plasma hormone ratios before and during ERT by the oral or parenteral route (geometrical mean values with $95 \%$ confidence limits of the mean)

\begin{tabular}{|c|c|c|c|c|c|c|c|}
\hline \multirow[b]{2}{*}{ Oestrogen ratios } & & \multicolumn{2}{|c|}{ Before therapy } & \multicolumn{2}{|c|}{ During oral ERT } & \multicolumn{2}{|c|}{ During parenteral ERT } \\
\hline & & & & & & & \\
\hline $\mathrm{Oe}_{1} \mathrm{~S} / \mathrm{Oe}_{1}$ & smokers $^{\mathrm{c}}$ & $6 \cdot 1$ & $(4 \cdot 0-9 \cdot 5)$ & $13 \cdot 6^{\mathrm{a}}$ & $(9 \cdot 2-20 \cdot 0)$ & $8 \cdot 2^{\mathrm{a}}$ & $(5 \cdot 9-11 \cdot 3$ \\
\hline $\mathrm{Oe}_{1} \mathrm{~S} / \mathrm{Oe}_{1}$ & non-smokers ${ }^{\mathrm{C}}$ & $7 \cdot 5$ & $(4 \cdot 4-12 \cdot 8)$ & $8 \cdot 5^{a}$ & $(6 \cdot 4-11 \cdot 4)$ & $13 \cdot 0^{\mathrm{a}}$ & $(8 \cdot 7-19 \cdot 4$ \\
\hline $\mathrm{Oe}_{1} \mathrm{~S} / \mathrm{Oe}_{2}$ & smokers $^{\mathrm{d}}$ & $18 \cdot 0$ & $(8 \cdot 1-40 \cdot 2)$ & $40 \cdot 2^{b}$ & $(28.5-67 \cdot 9)$ & $7 \cdot 0$ & $(4 \cdot 8-10 \cdot 2$ \\
\hline $\mathrm{Oe}_{1} \mathrm{~S} / \mathrm{Oe}_{2}$ & non-smokers & $12 \cdot 1$ & $(5 \cdot 2-27 \cdot 7)$ & $19 \cdot 1^{b}$ & $(12 \cdot 2-29 \cdot 8)$ & $11 \cdot 6$ & $(5 \cdot 0-26 \cdot 7$ \\
\hline $\mathrm{Oe}_{1} / \mathrm{Oe}_{2}$ & smokers ${ }^{\mathrm{c}}$ & $2 \cdot 9$ & $(1 \cdot 3-6 \cdot 5)$ & $3 \cdot 2$ & $(1 \cdot 5-4 \cdot 9)$ & $0 \cdot 8$ & $(0 \cdot 6-1 \cdot 2)$ \\
\hline $\mathrm{Oe}_{1} / \mathrm{Oe}_{2}$ & non-smokers & $1 \cdot 6$ & $(0 \cdot 8-3 \cdot 1)$ & $2 \cdot 1$ & $(1 \cdot 5-3 \cdot 1)$ & 0.9 & $(0 \cdot 5-1 \cdot 6)$ \\
\hline
\end{tabular}

$\mathrm{Oe}_{1}$, oestrone; $\mathrm{Oe}_{2}$, oestradiol; $\mathrm{Oe}_{1} \mathrm{~S}$, oestrone sulphate; significant difference between smokers and non-smokers (Mann-Whitney), ${ }^{\mathrm{a}} P<0 \cdot 05$, ${ }^{\mathrm{b}} P<0 \cdot 01$; significantly difference in the three test-situations (Friedman test), ${ }^{\mathrm{c}} P<0 \cdot 05,{ }^{\mathrm{d}} P<0 \cdot 01$.

Table 3 Plasma levels of sex hormone binding globulin before and during ERT by the oral or parenteral route (geometrical mean values with $95 \%$ confidence limits of the mean)

Before therapy

Sex hormone binding

globulin (nmol/l)

SHBG smokers $\quad 64.4$

SHBG non-smokers ${ }^{\mathrm{a}} \quad 41 \cdot 6$
During oral ERT

$88 \cdot 7$

$88 \cdot 0$

$\begin{array}{ll}(63 \cdot 4-124 \cdot 1) & 66 \cdot 2 \\ (58 \cdot 7-132 \cdot 0) & 50 \cdot 7\end{array}$

During parenteral ERT

$6 \cdot 2-(43 \cdot 9-99 \cdot 7)$

$(35 \cdot 1-73 \cdot 1)$

Significant difference in the three test-situations (Friedman test), ${ }^{a} P<0 \cdot 05$

The measurement of cotinine in plasma samples (five samples for every subject) confirmed the smoking status as reported by the patients. The cut-off value for cotinine in plasma used to discriminate between smokers and nonsmokers was $70 \mathrm{ng} / \mathrm{ml}$. The six smokers had cotinine levels in the range from 500 to $1000 \mathrm{ng} / \mathrm{ml}$. While seven non-smokers had cotinine levels $<7 \mathrm{ng} / \mathrm{ml}$ during the study period, one non-smoker had cotinine plasma values ranging between 70 and $280 \mathrm{ng} / \mathrm{ml}$. This patient denied any cigarette smoking on her own, but informed that she was living in a household with heavy in-door smoking.

\section{Discussion}

ERT is widely used in peri- and postmenopausal women with symptoms related to oestrogen deprivation. $\mathrm{Oe}_{2}$ given orally or by the percutaneous route increases plasma levels of $\mathrm{Oe}_{2}$ as well as $\mathrm{Oe}_{1}$ (Chetkowski et al. 1986, Lignieres et al. 1986). However, little is known about the influence of the different forms of ERT on plasma levels of $\mathrm{Oe}_{1} \mathrm{~S}$. While $\mathrm{Oe}_{1} \mathrm{~S}$ is biologically inactive on its own, most tissues are known to contain the enzymes necessary to convert $\mathrm{Oe}_{1} \mathrm{~S}$ into $\mathrm{Oe}_{1}$ and $\mathrm{Oe}_{2}$ (Santner et al. 1984). Considering the high plasma levels of circulating $\mathrm{Oe}_{1} \mathrm{~S}$, this steroid conjugate is suggested to be a major source for intra-tissue unconjugated oestrogens in postmenopausal women (Santner et al. 1986). Thus, any difference in plasma levels of $\mathrm{Oe}_{1} \mathrm{~S}$ related to the route of administration may contribute to the efficacy of the different oestrogen replacement regimens.

In this study, we examined the influence of route of administration and smoking on plasma oestrogens following treatment with ERT given orally and parenterally to 
the same patient group, eliminating confounding factors like interindividual response to enzyme inducing agents (Vesell \& Page 1969) and variation in life style like dietary habits (Longcope et al. 1987, Michnovicz \& Bradlow 1990). We hypothesised that ERT given orally would cause a more marked increase in plasma $\mathrm{Oe}_{1} \mathrm{~S}$ and the ratio of $\mathrm{Oe}_{1} \mathrm{~S}$ to $\mathrm{Oe}_{1}$ and $\mathrm{Oe}_{1} \mathrm{~S}$ to $\mathrm{Oe}_{2}$ compared with parenteral treatment. What we found was an increase in the ratio of $\mathrm{Oe}_{1} \mathrm{~S}$ to $\mathrm{Oe}_{2}$ during oral ERT compared with pretreatment levels and values obtained during parenteral treatment when evaluating the total group of patients. This finding, however, was due to a difference in smokers only; while the ratio of $\mathrm{Oe}_{1} \mathrm{~S}$ to $\mathrm{Oe}_{2}$ increased significantly during oral treatment compared with pretreatment values in smokers, no significant difference in the ratio of $\mathrm{Oe}_{1} \mathrm{~S}$ to $\mathrm{Oe}_{2}$ in the three test-situations was found among non-smokers. In addition, we found a significant increase in the $\mathrm{Oe}_{1} \mathrm{~S} / \mathrm{Oe}_{1}$ and $\mathrm{Oe}_{1} / \mathrm{Oe}_{2}$ ratio among smokers during oral ERT but no change in these ratios in non-smokers. Our observations are consistent with an enhanced first pass metabolism of $\mathrm{Oe}_{2}$ but also a preference for hepatic conversion of $\mathrm{Oe}_{2}$ to $\mathrm{Oe}_{1}$ as well as $\mathrm{Oe}_{1} \mathrm{~S}$ in smokers. We suggest the following explanation for these findings.

Oestrogens are metabolised by P450 dependent mixed function oxygenases (Bolt 1979). Cigarette smoking is known to enhance some of these mixed function oxygenases (Conney 1967) and has been found to stimulate 2-hydroxylation, a major metabolic pathway of oestrogens in man (Michnovicz et al. 1986).

In general, about $80-90 \%$ of orally given $\mathrm{Oe}_{2}$ is first pass metabolised in the splanchnic tissue (Longcope et al. 1985), leaving only about 10-20\% for the systemic circulation as unmetabolised $\mathrm{Oe}_{2}$. In contrast, $\mathrm{Oe}_{2}$ given by the transdermal route as well as endogenous oestrogens are directly passed into the circulation. If enhancement of liver enzymes due to cigarette smoking increased the extraction rate of $\mathrm{Oe}_{2}$, e.g. from 80 to $90 \%$ or 90 to $95 \%$, that would have little influence on the total plasma clearance rate of endogenous $\mathrm{Oe}_{2}$ or $\mathrm{Oe}_{2}$ administered parenterally. On the other hand, it may reduce the amount of $\mathrm{Oe}_{2}$ escaping first-pass metabolism following oral administration from 20 to $10 \%$ or 10 to $5 \%$ respectively, thus having a profound effect on plasma $\mathrm{Oe}_{2}$ levels after oral administration (Wilkinson \& Shand 1975, Longcope et al. 1985, Lønning \& Kvinnsland 1988).

The finding that smoking caused less suppression of plasma $\mathrm{Oe}_{1} \mathrm{~S}$ levels compared with $\mathrm{Oe}_{1}$ and $\mathrm{Oe}_{2}$ levels during oral therapy, but tended to suppress plasma $\mathrm{Oe}_{1} \mathrm{~S}$ during parenteral therapy, may seem contradictory. Considering $\mathrm{Oe}_{1} \mathrm{~S}$ as a 'low extracted compound' this may explain an influence of smoking on parenteral $\mathrm{Oe}_{1} \mathrm{~S}$ contrary to $\mathrm{Oe}_{1}$ and $\mathrm{Oe}_{2}$ (Wilkinson \& Shand 1975), while sulphation may probably slow down and protect metabolism of $\mathrm{Oe}_{1} \mathrm{~S}$ compared with $\mathrm{Oe}_{1}$ and $\mathrm{Oe}_{2}$ following oral administration. Other explanations may also be considered. Oestrogens undergo enterohepatic cycling (Bolt 1979), and drugs and food constituents are known to influence intestinal hydrolysis of biliary oestrogen conjugates and absorption (Dada \& Martins 1983). However, while an influence of smoking on enterohepatic cycling should have a similar influence on endogenous and exogenous oestrogen disposition, any direct influence of smoking on intestinal absorption of $\mathrm{Oe}_{2}$ cannot be ruled out.

There are additional mechanisms by which smoking may exert antioestrogen effects. Thus, nicotine has been shown to act as an aromatase inhibitor (Barbieri et al. 1986), substantiated by the observation of a reduced oestrogen/androgen ratio in smokers compared with nonsmokers (Longcope \& Johnston 1988, Law et al. 1997). While this may explain a difference in endogenous oestrogen levels between smokers and non-smokers and a reduced risk for oestrogen dependent malignancies like breast or endometrial cancer (Doll et al. 1980, Lesko et al. 1985), but increased risk for symptomatic osteoporosis (Daniell 1976) in smokers, it may not explain our observation of decreased oestrogen plasma levels in smokers following oral ERT.

Oestrogens in high concentrations are known to stimulate the synthesis of SHBG in hepatocytes (Anderson 1974), and the substantial increase during oral but not parenteral ERT may reflect a more profound oestrogen stimulation of the liver cells during oral therapy. Apart from sex hormones, agents inducing mixed function oxidases are known to elevate hormone binding globulins like SHBG (Toone et al. 1980). A balance between these influences could explain why smokers had somewhat higher plasma SHBG levels prior to ERT than nonsmokers but that the two groups experienced similar levels during oral ERT.

In conclusion, our results suggest oral and transdermal ERT to cause different ratios of plasma oestrogens in smokers, suggesting plasma $\mathrm{Oe}_{1} \mathrm{~S}$ as well as $\mathrm{Oe}_{1}$ and $\mathrm{Oe}_{2}$ measurements to be necessary whenever different treatment regimens are compared in scientific studies in this patient group. The finding that cigarette smoking decreased all plasma oestrogen levels during oral ERT by 40-70\%, but caused only minor changes in plasma $\mathrm{Oe}_{1} \mathrm{~S}$ during parenteral ERT, emphasises the need to consider smoking habits when prescribing ERT. In view of the number of patients involved in this study, our findings have to be considered as preliminary and should be confirmed in a larger group of patients.

\section{Acknowledgement}

This work was supported by grants from the Norwegian Cancer Society. The skillful technical assistance of Mrs H Berntsen is highly appreciated. 


\section{References}

Anderson DC 1974 Sex-hormone-binding globulin. Clinical Endocrinology 3 69-96.

Barbieri RL, Gochberg J \& Ryan KJ 1986 Nicotine, cotinine and anabasine inhibit aromatase in human trophoblast in vitro. Journal of Clinical Investigation 77 1727-1733.

Bolt HM 1979 Metabolism of estrogens - natural and synthetic. Pharmacology and Therapeutics 4 155-181.

Chetkowski RJ, Meldrum DR, Steingold KA, Randle D, Lu JK, Eggena P, Hershman JM, Alkjaersig NK, Fletcher AP \& Judd HL 1986 Biologic effects of transdermal estradiol. New England Journal of Medicine 314 1615-1620.

Conney AH 1967 Pharmacological implications of microsomal enzyme induction. Pharmacological Reviews 19 317-366.

Dada OA \& Martins OO 1983 Drug effects on the intestinal absorption of estrogens. Journal of Steroid Biochemistry 19 821-825.

Daniell HW 1976 Osteoporosis of the slender smoker: vertebral compression fractures and loss of metacarpal cortex in relation to postmenopausal cigarette smoking and lack of obesity. Archives of Internal Medicine 136 298-304.

Doll R, Gray R, Hafner B \& Peto R 1980 Mortality in relation to smoking: 22 years' observation on female British doctors. British Medical Journal 280 967-971.

Geola FL, Frumar AM \& Tataryn IV 1980 Biological effects of various doses of conjugated equine estrogens in postmenopausal women. Journal of Clinical Endocrinology and Metabolism $\mathbf{5 1}$ 620-625.

Kiel DP, Felson DT, Anderson JJ, Wilson PWF \& Moskowitz MA 1987 Hip fracture and the use of estrogens in postmenopusal women. New England Journal of Medicine 317 1169-1174.

Laufer LR, DeFazio JL, Lu JKH, Meldrum DR, Eggena P, Sambhi MP, Hershman JM \& Judd HL 1983 Estrogen replacement therapy by transdermal estradiol administration. American Journal of Obstetrics and Gynecology 145 533-540.

Law MR, Cheng R, Hackshaw AK, Allaway S \& Hale AK 1997 Cigarette smoking, sex hormones and bone density in women. European Journal of Epidemiology 13 553-558.

Lesko SM, Rosenberg L, Kaufman DW, Helmrich SP, Miller DR, Strom B, Schottenfeld D, Rosenshein NB, Knapp RC, Lewis J \& Shapiro S 1985 Cigarette smoking and the risk of endometrial cancer. New England Journal of Medicine 313 593-596.

Lignieres Bd, Basdevant A, Thomas G, Thalabard J-C, MercierBodard C, Conard J, Guyene T-T, Mairon N, Corvol P, Guy-Grand B, Mauvais-Jarvis P \& Sitruk-Ware R 1986 Biological effects of estradiol-17 $\beta$ in postmenopausal women: oral versus percutaneous administration. Journal of Clinical Endocrinology and Metabolism 62 536-541.

Lobo RA 1991 Effects of hormonal replacement on lipids and lipoproteins in postmenopausal women. Journal of Clinical Endocrinology and Metabolism 73 925-930.

Longcope C 1972 The metabolism of estrone sulfate in normal males. Journal of Clinical Endocrinology 34 113-122.

Longcope C \& Williams KIH 1974 The metabolism of estrogens in normal women after pulse injections of ${ }^{1} \mathrm{H}$-estradiol and ${ }^{1} \mathrm{H}$-estrone. Journal of Clinical Endocrinology and Metabolism 38 602-607.

Longcope C \& Johnston CC 1988 Androgen and estrogen dynamics in pre- and post-menopausal women: a comparison between smokers and nonsmokers. Journal of Clinical Endocrinology and Metabolism 67 379-383.

Longcope C, Gorbach S, Goldin B, Woods M, Dwyer J \& Warram J 1985 The metabolism of estradiol; oral compared with intravenous administration. Journal of Steroid Biochemistry 23 1065-1070.

Longcope C, Gorbach S, Goldin B, Woods M, Dwyer J, Morill A \& Warram J 1987 The effect of a low fat diet on estrogen metabolism. Journal of Clinical Endocrinology and Metabolism 64 1246-1250.
Lønning PE \& Kvinnsland S 1988 Mechanisms of action of aminoglutethimide as endocrine therapy of breast cancer. Drugs 35 685-710.

Lønning PE, Kvinnsland S, Thorsen T \& Ueland PM 1987 Alterations in the metabolism of oestrogens during treatment with aminoglutethimide in breast cancer patients. Preliminary findings. Clinical Pharmacokinetics 13 393-406.

Lønning PE, Johannessen DC \& Thorsen T 1989 Alterations in the production rate and the metabolism of oestrone and oestrone sulphate in breast cancer patients treated with aminoglutethimide. British Journal of Cancer $\mathbf{6 0} 107-111$.

Lønning PE, Helle SI, Johannessen DC, Adlercreutz H, Lien EA, Tally M, Ekse D, Fotsis T, Anker GB \& Hall K 1995 Relations between sex hormones, sex hormone binding globulin, insulin-like growth factor-I and insulin-like growth factor binding protein-1 in post-menopausal breast cancer patients. Clinical Endocrinology 42 23-30.

Mandel FP, Geola FL, Meldrum DR, Lu JHK, Eggena P, Sambhi MP, Hershman JM \& Judd HL 1983 Biological effects of various doses of vaginally administered conjugated equine estrogens in postmenopausal women. Journal of Clinical Endocrinology and Metabolism 57 133-139.

Meade TW 1982 Oral contraceptives, clotting factors and thrombosis. American Journal of Obstetrics and Gynecology 142 758-761.

Michnovicz JJ \& Bradlow HL 1990 Induction of estradiol metabolism by dietary indole-3-carbinol in humans. Journal of the National Cancer Institute 82 947-949.

Michnovicz JJ, Hershcopf RJ, Naganuma H, Bradlow HL \& Fishman J 1986 Increased 2-hydroxylation of estradiol as a possible mechanism for the antiestrogenic effect of cigarette smoking. New England Journal of Medicine 315 1305-1309.

Muranaka H, Higashi E, Itani S \& Shimizu Y 1988 Evaluation of nicotine, cotinine, thiocyanate, carboxyhemoglobin and expired carbon monoxide as biochemical tobacco smoke uptake parameters. International Archives of Occupational and Environmental Health $\mathbf{6 0}$ $37-41$.

Nabulsi AA, Folsom AR, White A, Patsch W, Heiss G, Wu K \& Szklo M 1993 Association of hormone-replacement therapy with various cardiovascular risk factors in postmenopausal women. New England Journal of Medicine 328 1069-1075.

Ruder HJ, Loriaux L \& Lipsett MB 1972 Estrone-sulfate: production rate and metabolism in man. Journal of Clinical Investigation $\mathbf{5 1}$ 1020-1033.

Santner SJ, Feil PD \& Santen RJ 1984 In situ estrogen production via the estrone sulfatase pathway in breast tumors: relative importance versus the aromatase pathway. Journal of Clinical Endocrinology and Metabolism 59 29-33.

Santner SJ, Leszcynski D, Wright C, Manni A, Feil PD \& Santen RJ 1986 Estrone sulfate: a potential source of estradiol in human breast cancer tissue. Breast Cancer Research and Treatment 7 35-44.

Toone BK, Wheeler M \& Fenwick PBC 1980 Sex hormone changes in male epileptics. Clinical Endocrinology 12 391-395.

Vesell ES \& Page JG 1969 Genetic control of the phenobarbitalinduced shortening of plasma antipyrine half-lives in man. Journal of Clinical Investigation 48 2202-2209.

Waage H, Silsand T, Urdal P \& Langård S 1992 Discrimination of smoking status by thiocyanate and cotinine in serum and carbon monoxide in expired air. International Journal of Epidemiology 21 488-493.

Wilkinson GR \& Shand DG 1975 Commentary: a physiological approach to hepatic drug clearance. Clinical Pharmacology and Therapeutics 18 377-390.

Received 5 November 1998

Accepted 31 March 1999 